\title{
O MÉTODO DE ENSINO LANCASTERIANO: UMA COMPARAÇÃO ENTRE A SALA MONITORAL DO THE BRITISH SCHOOL MUSEUM DE HITCHIN, NA INGLATERRA, E O REGIMENTO INTERNO DAS AULAS PÚBLICAS DAS PRIMEIRAS LETRAS DA PROVÍNCIA DO ESPÍRITO SANTO EM 1871
}

DOI: http://dx.doi.org/10.1590/2236-3459/41842

\author{
Dirce Nazaré de Andrade Ferreira \\ Universidade Federal do Espírito Santo, Brasil. \\ Cleonara Maria Schwartz \\ Universidade Federal do Espírito Santo, Brasil.
}

\author{
Aloisio Krohling
}

Faculdade de Direito de Vitória, Brasil.

\section{$\cos 80$}

\begin{abstract}
Resumo
Este texto é resultado de uma pesquisa de campo qualitativa, exploratória e descritiva realizada no British School Museum, na cidade de Hitchin, na Inglaterra, com vistas a investigar o método lancasteriano em um espaço lúdico denominado sala monitorial. A pesquisa empírica se desenvolveu com observação dirigida a partir da análise da sala monitorial e de seus ferramentais lúdicos para, depois, cotejá-los com o Regimento Interno das Aulas Públicas das Primeiras Letras do Espírito Santo, de 1871, e com os livros de Joseph Lancaster, que descrevem seu método. Desta forma, a triangulação relacional entre a sala monitorial, o Regimento de 1871 e os livros de Joseph Lancaster forneceu uma síntese para entender as estratégias de ensino aplicadas em Londres e que se incorporaram nas estratégias pedagógicas do Brasil no século 19.

Palavras-chave: British School Museum, monitorial, história, educação, legislação.
\end{abstract}


THE LANCASTERIAN METHOD: A COMPARISON BETWEEN THE ROOM MONITORAL OF THE BRITISH MUSEUM SCHOOL IN ENGLAND, AND THE CHARTER OF THE PUBLIC SCHOOLS OF THE FIRST LETTER OF THE PROVINCE ESPÍRITO SANTO 1871

Abstract

This article is the result of a qualitative research, exploratory and descriptive held in the British Museum School, in Hitchin, in order to study the Lancasterian Method, in a playful space called monitorial room. The research was developed with the empirical observation led to the analysis of the object and its tooling playful compare them with Regimento Interno das Aulas Públicas das Primeiras Letras do Espírito Santo de 1871, and Joseph Lancaster's books that describe your method. Thus, the triangulation between relational objects of study provided an overview to understand the teaching strategies applied in London and are incorporated in the teaching strategies of Brazil in the nineteenth century.

Key-words: British Museum School, monitory, history, education, legislation.

\title{
EI MÉTODO LANCASTERIANO: UNA COMPARACIÓN ENTRE LA SALA MONITORAL DE LA INGLATERRA Y LA CARTA DE LAS ESCUELAS PÚBLICAS DE LA PRIMERA CARTA DE LA PROVINCIA DEL ESPÍRITO SANTO EN 1871
}

\section{Resumen}

Este artículo es el resultado de una investigación cualitativa de campo, exploratorio y descriptivo realizado en la Escuela Museo Británico de la ciudad de Hitchin, en Inglaterra, con el fin de encontrar el método lancasteriano en un espacio lúdico llamado sala de monitores. La investigación empírica se ha desarrollado con la declaración dirigida al análisis de la habitación y su utillaje monitorizada juguetón y luego compararlos con las normas internas de las clases públicas de primeras letras del Espíritu Santo, de 1871, y los libros que describen Joseph Lancaster su método. Así, la triangulación entre relacional sala de monitores, el regimiento en 1871 y los libros de Joseph Lancaster dio una visión general para comprender las estrategias de enseñanza que se aplican en Londres y se han incorporado en las estrategias de enseñanza de Brasil en el siglo 19.

Palabras-clave: British Museum School, monitorizada, historia, educación, legislación.

\section{LE LANCASTERIANO MÉTHODE: UNE COMPARAISON ENTRE LA SALLE MONITORAL DU MUSÉE BRITISH SCHOOL OF HITCHIN EN ANGLETERRE ET LA CHARTE DES ÉCOLES PUBLIQUES DE LA PREMIÈRE LETTRE DE LA PROVINCE DU SAINT-ESPRIT EN 1871}

\begin{abstract}
Résumé
Cet article est le résultat d'une recherche qualitative sur le terrain, exploratoire et descriptive qui s'est tenue à l'École du British Museum dans la ville de Hitchin en Angleterre, afin de trouver la méthode Lancasteriano dans un espace ludique appelée chambre des moniteurs. La recherche empirique a été développé avec la déclaration adressée à l'analyse de la pièce et son outillage monitory ludique et de les comparer avec les règles internes de leçons publiques des Premières Lettres de l'Esprit Saint de 1871, et les livres qui décrivent Joseph Lancaster sa méthode. Ainsi, la triangulation entre la salle des moniteurs relationnel, le régiment en 1871 et les livres de Joseph Lancaster a donné un aperçu de comprendre les stratégies d'enseignement appliquées à Londres et sont intégrées dans les stratégies d'enseignement du Brésil au $19^{\mathrm{e}}$ siècle.

Mots-clé: British Museum scolaires, monitory, histoire, education, législation.
\end{abstract}




\section{Apresentação}

A história da educação na Província do Espírito Santo do século 19 é um espaço aberto para inúmeras possibilidades de investigação. A relevância de estudar a memória educacional de um determinado espaço geográfico representa o importante exercício de convocar o passado para se debruçar sobre suas fontes e narrativas para, a partir delas, entender a pulsão referencial de seus relatos e, então, revelar as práticas contidas nas fontes pesquisadas.

Este artigo é parte da pesquisa de campo realizada durante o curso de doutorado em História Social das Relações Políticas, uma vez que o objeto de estudo desenvolvido se refere ao método lancasteriano ou monitorial na história da educação do Espírito Santo. Trata-se de um relevante corpus pedagógico criado em Londres no início do século 19 pelo pastor quacker Joseph Lancaster, com a perspectiva de expandir a escolaridade à população empobrecida da Inglaterra. $O$ trabalho de Joseph Lancaster alcançou outros países, dentre eles os Estados Unidos, e na América do Sul, dentre outros, a Venezuela e o Brasil.

Arruda (1996) argumenta que, no Brasil pós-independente do século 19, o Estado necessitava estruturar as instituições para compor formalmente seus quadros burocráticos e plasmar a imagem de neonação. Desta forma a escolaridade foi um ferramental utilizado pelo Estado para articular as aspirações do regime monárquico com a formação educacional do povo, sendo o ensino tutelado pelo ideário da religião católica, uma vez que, pela Constituição de 1824, não havia laicidade no Brasil.

Como o método lancasteriano se mostrava aderente aos ideais conservadores da Igreja e da Monarquia e se propunha a escolarizar o povo pelas vias instrucionais de estratégias rápidas e de baixo custo, em 1827 a Lei Januário da Cunha Barbosa, de 15 de outubro, além de tornar obrigatória a criação de escolas em todas as cidades, instituiu o método lancasteriano ou método monitorial como a primeira técnica formal de ensino no Brasil.

A adoção do método lancasteriano por lei nacional atribuía ao território brasileiro como um todo, cumprir a pauta educacional monitorial, daí que nosso locus de pesquisa é a Província do Espírito Santo, no período de 1827 a 1871. Essa fatia temporal se justifica por que em 1827 o método lancasteriano foi formalizado e, desde então, passou a constar nos documentos formais da Província, tendo seu ápice em 1871, quando da escrita do Regimento Interno das Primeiras Letras da Província do Espírito Santo. Durante quase cinco décadas o método lancasteriano norteou a educação na Província capixaba, sendo que o declínio do método monitorial ocorreu com o fim do Império em função dele ser associado ao conservadorismo do Regime Monárquico.

Segundo Maria Helena Câmara Bastos (1999), o trabalho de Joseph Lancaster representou um planejamento bem definido de ações, descrevendo desde as instalações prediais escolares, o currículo pedagógico, a forma de ensinar, até os instrumentais utilizados nas salas de aula. Sintetizando o pensamento da autora, enfatizamos que o trabalho de Lancaster é um conjunto intrincado de ações e, diante de tal complexidade, neste artigo, fizemos um recorte para analisar somente os instrumentais usados na sala pedagógica monitorial, com destaque que esse recurso pedagógico é relevante, mas nem por isso único, pois o trabalho lancasteriano é um conjunto substancial de ideias pedagógicas engenhosas e bastante criativas para a época. 
Para elaborar a trajetória do método lancasteriano e destacar os contornos mais elaborados do ensino, buscamos nas fontes primárias as principais estratégias descritas pelo autor. Adquirimos, em Londres, os livros escritos por Joseph Lancaster: The improvements in educations (1803), The british system of education (1812) e The lancasterian system of education (1821). A partir desses documentos o método foi sendo descortinado e passamos a sua apreciação no Brasil a partir do locus analisado, qual seja, o Estado do Espírito Santo pelas vias dos historiadores Terezinha Tristão Bichara (1984), Gabriel Bittencourt (2006) e José Teixeira de Oliveira (2008).

Para tanto, pesquisamos uma amostra da legislação brasileira sobre educação: a Constituição Federal de 1824 e o Regimento Interno das Escolas de Primeiras Letras do Espírito Santo, este último é um instrumental normativo composto por mais de 90 artigos, que descrevem a dinâmica das escolas elementares da Província, no final do século 19, e que apresentam muitos traços do método lancasteriano.

Busca-se abordar a história oficial da educação na Província do Espírito Santo durante as primeiras cinco décadas do século 19. Os principais balizamentos do trabalho são documentos e leis formalmente aprovadas no Brasil pós-independente. Como se trata de um importante período histórico em que o Estado nacional necessitava assentar suas bases para se fortalecer, a legislação foi uma fonte que nutriu a racionalidade.

A educação lancasteriana foi uma estratégia inserida na legislação, na perspectiva de formalizar e organizar o sistema de educação, logo, esses expedientes concorreram para que o período ofertasse farta documentação escrita em forma de leis sobre a temática pesquisada. Porém, não encontramos no Espírito Santo nenhum tipo de fonte contendo desenhos, elementos pictóricos ou lúdicos que fossem capazes de melhor ilustrar o método lancasteriano, descrito com detalhes na legislação brasileira, com ênfase no Regimento de 1871 do Espírito Santo.

Daí que a partir de pesquisas em universidades da Inglaterra, berço do método lancasteriano, entramos em contato com The British School Museum na cidade de Hitchin, na perspectiva de obter mais informações sobre o autor e sua obra, na perspectiva de compará-la com o modelo descrito no Regimento de 1871. A instituição informou que além de obter outro corpus documental sobre Joseph Lancaster arquivado em seus anais, tinha também um espaço denominado sala lancasteriana ou sala monitorial, uma espécie de câmara didática demonstrativa. Trata-se de uma sala de aula preservada, que contém alguns materiais originais e outros remodelados do trabalho de Joseph Lancaster. O Museu ressaltou, também, que a salvaguarda da sala de aula monitorial se deve ao fato de que naquele espaço funcionou, no século 19, uma escola de ensino que utilizava o método lancasteriano.

A partir dessas premissas fizemos uma visita técnica ao The British School Museum, na qual obtivemos acesso aos livros, documentos sobre o tema e nas salas monitorial The monitorial schoolroom, The edwardian schoolroom e a The gallery classroom -, as quais, enquanto objetos de pesquisa, foram fotografadas e filmadas. Como produto desse trabalho de campo geramos este artigo com os objetivos de revelar a antiga escola e suas fontes históricas de pesquisas, perscrutar os conhecimentos sobre a temática e, principalmente, responder as seguintes questões: quais as estratégias pedagógicas utilizadas na sala monitorial do museu visitado? Em que aspectos as instalações, os 
materiais pedagógicos e as táticas de ensino utilizadas na sala monitorial do The British School Museum se alinham à proposta pedagógica brasileira descrita no Regimento Interno de 1871 das Escolas de Primeiras Letras, no Estado do Espírito Santo?

A pesquisa de campo foi orientada e acompanhada pela diretoria da instituição que, além de disponibilizar os livros e documentos sobre a obra de Joseph Lancaster, assistiu ao desenvolvimento da investigação no campo, dirimindo as dúvidas sobre os instrumentos pedagógicos e possibilitando a coleta de dados e fotografias sobre os materiais escolares da sala monitorial.

Logo, partindo da taxionomia de Vergara (2009), a metodologia utilizada neste artigo é a de uma pesquisa exploratória e descritiva combinada com observação dirigida, pois há um trabalho de campo ou empiria. No trabalho usamos como norteador o método indiciário de Carlos Ginzburg (1989), a partir da análise qualitativa do objeto, combinada ao método comparativo, já que analisamos os materiais lúdicos contidos na sala monitorial, cotejando-os com o Regimento de 1871 e com os livros de Joseph Lancaster que descrevem seu método. Desta forma, a triangulação relacional estabelecida entre as fontes forneceu uma síntese coerente entre elas.

\section{The British School Museum: a memória lúdica da educação inglesa}

O edifício onde funciona The British School Museum é representativo da memória educacional inglesa, pois naquele local funcionou, em 1810, a primeira escola para meninos da cidade de Hitchin, na Inglaterra. Luciano Faria Filho (2006, p. 7) ressalta que "as implicações da escolarização apreendidas a partir da história cultural lida com as práticas e representações dos sujeitos envolvidos na história social”.

Logo, preocupados com as feições sociais que cercam a educação e que se projetam a outros locus, é que passamos a estudar um recorte temporal da história educacional inglesa para deslindar em que aspectos ela interage com a história educacional do Brasil. A história do British Musem, ao abrigar a sala monitorial, é prova de que a história e a educação são caminhos complementares e na cultura educacional é possível entender sob quais aspectos políticos as trilhas da sociedade são traçadas. $O$ British School Museum é fonte na qual a história da educação brasileira se apoiou então passamos a percorrer este sustentáculo de informações.

Construído pelo advogado William Wilshere, o edifício principal evoca reminiscências do século 19. Com ele há outras casas memoriais que formam um conjunto de prédios com arquitetura típica londrina, cuja estética da construção com tijolos vermelhos parecem abraçar quem chega.

Tudo começou em 1810 e a partir disso o prédio ganhou vida e se tornou escola museu e memória.

Embora o primeiro prédio muito rústico de 1810 tenha sido reconstruído e dele quase nada mais se tenha de original a não ser a "a pedra fundamental onde se lê: 1810 W.W. e que está incorporada desde 1837 no prédio onde funcionou a escola dos meninos" (British Schools Museum, 1999, p. 2), entrar no prédio é como ter acesso vivo à Londres antiga do século 19. 
O prédio de 1810 continha uma sala que poderia abrigar 150 alunos e foi a primeira na cidade de Hitchin a utilizar o Método Monitorial, ou "a escola para os filhos dos trabalhadores pobres. Este sistema de educação foi iniciado pelo quaker Joseph Lancaster" (British Schools Museum, 1999, p. 2). Em 1819 foi iniciada uma sala de aula para meninas.

Em 1824 o proprietário William Wilshere faleceu e deixou a escola para seu amigo Lord Dacre, sendo que dois anos mais tarde o educandário passou a receber subvenções de mantenedores, muitos deles religiosos, e que apoiavam a causa caritativa de prover educação aos menos favorecidos. Em 1835 a quantidade de alunos se ampliou consideravelmente, sendo necessário fazer alterações prediais.

Destaca-se que que "os mantenedores resolveram construir um novo prédio capaz de abrigar 300 alunos, cujo número que estimaram foi rapidamente se elevando" (British Schools Museum, 1999, p. 4). A nova escola foi construída de forma quase idêntica à escola de Borough Road, pensada por Joseph Lancaster: "uma sala retangular com colunas de madeira nas laterais e amplas janelas com grades e o piso inclinado" (p. 4).

Em 1854 a sala de aula das alunas e parte da Infant's School foram destruídas por um incêndio, mas a escola foi reconstruída, "porém com paredes mais finas e teto mais baixo." Em 1855 o inspetor Mattew Arnolds sugeriu que "a escola pudesse ter monitores [na sala das meninas], mas que seria desejável substituir teto e paredes como também fazer novo arranjo de carteiras, cortinas e providenciar aquecedor para a sala de aula" (British Schools Museum, 1999, p. 12).

Destaque-se que as configurações da sala de aula descritas por Joseph Lancaster previam que a escola deveria ter o piso inclinado para alocar a mesa do professor em local mais elevado, de modo que fosse possível visualizar a sala por inteiro. De acordo com o que foi pesquisado as dimensões prediais lancasterianas eram exigidas pelo Conselho de Educação Britânica, que fazia auditorias in loco nas escolas para adequar as salas de aulas. Após providenciar as melhorias solicitadas, em 1856 a escola as submeteu ao Comitê do Conselho de Educação, que exigiu outras mudanças na sala de aula:

o piso da escola deveria ser rebaixado em 14 polegadas, e que a nova escola [remodelada] deveria ter altura [do teto] e espessuras de janelas [...] a área de recreação deveria ser ampliada. Deveria também derrubar o antigo prédio e construir um ou dois cômodos para a sala dos professores. (British Schools Museum, 1999, p. 12)

O Comitê ressaltou, também, que essas sugestões em muito aperfeiçoariam a aparência do prédio escolar, já que este está situado "em uma rua principal da cidade, então seria interessante para os professores e para a escola" (British Schools Museum, 1999, p. 12).

Em junho de 1857 o grupo decidiu aceitar a proposta para reconstruir completamente a escola, sendo que as obras foram concluídas em 1858. Quando o inspetor Matthew Arnold visitou a escola, em 1867, ressaltou a adequação predial e destacou "a excelente instalação predial que tinha sido construída desde a última verificação que fiz nesta escola" (British Schools Museum, 1999, p. 12). 
A escola foi se transformando e várias alterações prediais menores foram feitas entre 1899 e 1901, com destaque para a de 1907, cuja importância é fundamental, pois foram construídos banheiros na escola. Outro destaque para o início do século 20 foi a exigência de uma escada para o acesso às salas das meninas, que permanece no mesmo local até hoje: uma estrutura de ferro negro que representa o início de uma nova era para a escola, imersa que estava, na sociedade industrial.

Nas primeiras décadas do século 20 a escola passou por outras modificações e em maio de 1940 a escola estava quase vazia, caindo em um estado de abandono, precisando de reparo e correndo riscos de demolição. Em 1969 a última classe da escola foi encerrada, mas o prédio continuou a ser usado como Hitchin College's Community Annex. Foi então que em 1975 Jill E. Grey adquiriu o complexo predial, um importante sítio com significado histórico, tanto para a educação, quanto para a história da arquitetura escolar. Em 1977 foi reconhecida a contribuição do conjunto arquitetônico e da história do prédio, sendo que a escola foi transformada em Museu, sendo-lhe atribuído o título The British School Museum.

O Museu apresenta três momentos ilustrados em salas de aula, pelos quais procura demonstrar como a educação elementar passou por alterações, tanto nos métodos, quanto nos materiais pedagógicos e códigos atitudinais desenvolvidos na escola. São eles: The lancasterian school room, The gallery class room, and The edwardian. Cada sala representa um modelo escolar no tempo, com suas idiossincrasias e tipicidades. Ocorre que a história não é estanque e, embora as salas sejam pedagogicamente separadas pelos critérios de espaço e tempo, é possível perceber que as informações entre elas se mesclam em um conjunto de dados e relatos que não serão vistas fracionadamente pelo pesquisador. Neste caso, Faria Filho (2006, p. 7) refere que "a atenção volta-se para o sincrônico, para as implicações e dimensões sociais, culturais e políticas", que formam um compósito contíguo na educação.

Como nosso interesse neste artigo recaiu sobre a sala lancasteriana, é sobre esse conjunto de informações lúdicas e pedagógicas que passamos a discorrer, embora não descartemos que em alguns momentos possamos resgatar elementos das demais salas, que embora não presentes no espaço monitorial a ele pertencem enquanto momento pioneiro na educação londrina.

\section{A sala monitorial e os instrumentos pedagógicos de Joseph Lancaster no The British School Museum}

Desde logo cabe-nos explicar a simplicidade da sala monitorial. Construída em 1837 para abrigar 300 alunos, com o auxílio de 30 monitores e um professor, o espaço é uma reprodução das exigências do método lancasteriano. Segundo The British School (1999, p. 5) a sala monitorial "é o único exemplo conhecido e completo no mundo", uma transcrição pictórica preservada em forma de móveis, utensílios e materiais pedagógicos.

A sala é essencialmente a mesma de 1837, construída com as especificações do Método Monitorial, inclusive por que o Conselho de Educação Britânico determinava que fossem cumpridas as exigências da pauta educacional lancasteriana. A sala é um amplo espaço com iluminação e ventilação adequadas para receber alunos. A configuração das janelas permite à luz solar prover um ambiente claro no verão. No inverno é usada iluminação elétrica e aquecedores. 
O teto da sala é bem elevado para causar impressão de ambiente amplo que, por sua vez, traz maior sensação de conforto uma vez que o local é claro, limpo e asséptico, produzindo boa impressão.

Quando Lancaster substituiu o livro individual dos alunos por uma única cópia impressa, ampliada em tamanho maior que poderia ser visualizada pela classe inteira, era uma ideia que primava pela economicidade na escola. Assim, o método lancasteriano, além de demonstrar custos acessíveis conseguiu, pela racionalidade que lhe era peculiar, alfabetizar os alunos em tempo menor. Com isso, a equação economia de recursos e diminuição de tempo na escola se adicionava à ampliação da escolarização, fazendo do método um importante aliado do Estado.

O método de ensino lancasteriano no regimento interno das escolas de primeiras letras do Espírito Santo de 1871 e a sala monitorial do British School Museum, na Inglaterra: um alinhamento pedagógico em sintonia

Tão importante foi o trabalho de Joseph Lancaster nos primeiros anos do século 19 que se expandiu pelo mundo, chegando ao Brasil em 1827. Faria Filho (2006, p. 9) aponta que "animados que estavam com a recém conquistada independência, dizia-se que a cultura do espírito aumenta a felicidade dos homens, então se deve propor um projeto de instrução que abrevie o tempo das crianças na escola e diminua os custos". Eis que no período das grandes codificações essas premissas deveriam constar nas leis.

Na Província do Espírito Santo foi criada a Directoria da Instrucção Publica, que em 1871 redigiu um importante documento denominado Regimento Interno das Aulas Públicas das Primeiras Letras da Província do Espírito Santo. Em nossa pesquisa não encontramos quaisquer outros resquícios de como o Regimento fora escrito, quais as pessoas que o escreveram e quais debates giraram em torno de sua confecção. Mas seu conteúdo não deixa imprecisões sobre seus objetivos e, sobretudo, quanto aos balizamentos lancasterianos formalizados na educação.

$\mathrm{Na}$ verdade, os documentos formais mantidos no Arquivo Público do Espírito Santo atestam a existência do método lancasteriano na Província muito antes de 1827, mas é o Regimento de 1871 o mais robusto memorial que demonstra a aderência da educação brasileira com o Método Monitorial. Essa fusão é fortalecida pela descrição das práticas culturais e religiosas subjacentes ao método lancasteriano que foi inserido na escola brasileira e formou com ela uma conexão política.

O Regimento é, portanto, um atestado da predominância da cultura européia no Brasil do século 19, principalmente, na educação. O documento ora analisado descreve, em seus 90 artigos, quase todo o trabalho educacional de Joseph Lancaster contidos nos livros Improvements in education (1807) e The british system of education (1812). Por questões de adequação aos nossos objetivos, delimitamos nosso espaço de análise à sala monitorial, um dos instrumentos pedagógicos descritos no Regimento de 1871, e que consta no The British School Museum como espaço de representação educacional, mas que não é o único recurso do método lancasteriano.

Na obra The british system of education (1812), Lancaster destaca que o sucesso da educação não poderia ser alcançado sem uma sala de aula apropriada. Destaca que "todas as cadeiras deveriam estar [perfiladas] com a frente voltada para a mesa do professor" (Lancaster, 1812, p. 1). Além disso o piso da sala deveria apresentar uma 
inclinação de maneira a posicionar a mesa do professor na parte mais elevada, para que fosse providenciada a ele uma visão geral do ambiente de forma que pudesse controlar melhor a turma, evitando inadequações na conduta dos alunos ou indisciplina. Dada às configurações prediais da classe escolar, o piso deveria ser de madeira, a ponto de não produzir ruídos indesejados que obstruíssem o bom andamento das atividades pedagógicas. A sala deveria ter de preferência a forma geométrica de um quadrado ou retângulo com

o comprimento com mais de dois terços da largura. O chão deveria estar em um plano inclinado, e o professor posicionado [em um estrado rodeado de degraus] na parte inferior da elevação [na base]. A inclinação [seria de tal modo] que causaria elevação das últimas fileiras de banco, e isso possibilitaria ao professor visualizar de sua mesa, todos os alunos da escola. (Lancaster, 1821, p. 1)

$\mathrm{Na}$ sala monitorial os bancos são assentos coletivos, confeccionados em madeira, sem encosto para as costas e dispostos em fileiras na ordem hierárquica de primeira à oitava séries, equivalendo em um ordenamento de 1 a 8 , conforme predisposição do conteúdo pedagógico, o que corresponde na sala monitorial às oito fileiras de bancos ou classes, todas elas com conteúdo analítico dedutivo que iria do mais simples ao mais complexo, em uma gradação sincrônica.

Em conformidade com a sala monitorial, o Regimento de 1871 , ao descrever os objetos usados na classe exige que haja "bancos e escrivaninhas inclinados, com tinteiros fixos, colocados em frente ou ao lado do professor" (art. 90, $\S 7^{\circ}$ ). Esse arranjo já denota duas características contidas, tanto na sala monitorial, quanto no Regimento de 1871: a hierarquia e a disciplina. Segundo Faria Filho (2006, p. 39), essas duas características casam muito bem "com a sociedade brasileira oitocentista marcada pela transição da colônia ao Império, que necessitava estruturar-se" e, para tanto, a disciplina e a hierarquia eram fatores primordiais.

A hierarquia é observada de imediato, pois a mesa do professor deveria ser posta "sobre uma elevação do piso de seis polegadas de altura nos primeiros vinte passos a partir da mesa do professor, depois dessa distância [a inclinação] a cada vinte passos se elevaria" (Lancaster, 1812, p. 1).

Da mesma forma que a recomendação de Lancaster, na sala monitorial do Museu a mesa do professor chama atenção por sua cor e austeridade, em madeira mais escura, posta sobre a parte elevada da sala. Acima do chão erguido a mesa tem um púlpito que a torna mais alta. Diz Foucault (2004, p. 23) que isso era similar a "um posto de vigilância em que fosse possível visualizar a sala por inteiro". Esse processo de vigilância se adequava muito bem ao momento brasileiro, na perspectiva de "civilizar o povo e assim manter a ordem para melhor governar" (Faria Filho, 2006, p. 24).

Em consonância com Lancaster e com a sala monitorial, o Regimento de 1871, no artigo 90, destaca que "em cada aula [sala] deveria ter [...] um estrado de um palmo de altura e com dimensões suficientes para conter uma cadeira para o professor e uma mesa com duas gavetas". O estrado com um palmo de altura é o mesmo púlpito da sala monitorial do Museu. Logo, os dois standards analisados - Museu Inglês e o Regimento de 1871 - estão em consonância quanto ao elemento hierarquia e disciplina, embora se 
reconheça que as duas palavras são polissêmicas, se enredando em outros significados. Mas a mesa docente representa um símbolo de hierarquia e poder nas duas fontes analisadas.

Vê-se que sobre a mesa do professor no Museu Britânico há uma bíblia e um chapéu característico do início do século 19, símbolo de autoridade docente. Em destaque da sala monitorial, a Bíblia sobre a mesa do professor também era a personificação de disciplina e temor a Deus. Coerente com a sala monitorial londrina, no Regimento de 1871 consta que na Província do Espírito Santo deveriam ser ministradas as aulas de religião e, no rol dos livros exigidos, além da Bíblia, era recomendado "o cathecismo da doutrina christã, a história sagrada, e a história da igreja".

Ainda sobre a mesa docente da sala monitorial há um código de conduta para o aluno resumido nos seguintes vocábulos: "seja honesto, obediente, diligente, atencioso, asseado e organizado, civil, calado, dócil, modesto, e sempre chegue cedo" (British Museum, 1999). Essa permanência do código de conduta sobre a mesa do professor é similar ao artigo 90 do Regimento de 1871 que exigia constar sobre a mesa do professor "um Regulamento Geral e um Interno" (§ 17) descrevendo toda a dinâmica da sala de aula, e principalmente da conduta dos atores educacionais.

$\mathrm{O}$ artigo $4^{\circ}$ do Regimento descreve os deveres dos alunos: "o aluno deve conservarse na sala, em ordem, respeito e atenção [...] sempre debaixo do maior silêncio". O Regimento repete em muitos artigos a expressão "debaixo do maior silêncio", como uma forma reforçadora da conduta civilizada, exigida ao aluno em sala de aula, e fora dela.

Como regra de conduta e civilidade destaca-se, também, que no século 19 um costume europeu chamava a atenção: o uso dos chapéus como símbolo de cidadania, inclusive pelas crianças. Assim, no British School Museum se destaca um artefato ricamente preservado na entrada da sala monitorial: trata-se de um chapeleiro ou como escreveu Lancaster "um aparato para guardar chapéus [...] isto previne perdas ou erros e confusões para encontrá-los, [fatos] tão comuns onde há grande número de meninos" (Lancaster, 1812, p. 3).

O chapeleiro do Museu é um cabide de ferro pintado na cor preta, acoplado na parede em frente à porta de entrada da sala de aula, como a informar que a ordem e civilidade eram cumpridas antes da entrada na sala monitorial. $\mathrm{O}$ acesso à sala monitorial era considerada como um rito sagrado. No espaço pedagógico não havia espaço para os cavalheiros usarem chapéus considerados adornos reservados à rua, espaço livre, público, de lazer e recreação. Os chapéus dos alunos deveriam estar do lado de fora da sala monitorial, no cabide.

Em consonância com a sala monitorial inglesa, o Regimento de 1871 no Brasil, também exigia que na sala de aula houvesse "dous cabides para os chapeos" (art. 90, § 12). Como se pode observar a forma de organização na sala de aula e a atitude de guardar os chapéus era um elemento denotativo de disciplina e ordem. Destaque e diferença, todavia, é dada à permanência do chapéu do professor sobre sua mesa na sala monitorial. Embora não haja referência nos livros de Lancaster sobre essa temática, entendemos que a presença do chapéu docente na sala monitorial pode ser uma simbologia para demarcar o espaço hierárquico entre aluno e professor, pois este representava autoridade na sociedade do século 19. Seu chapéu, portanto, era 
diferenciado daqueles usados pelos alunos: mais alto, negro e de estrutura bem reforçada e que, portanto, poderia permanecer na sala monitorial, como um fator impositivo de disciplina.

Outro elemento que se refere à disciplina e que está presente, tanto no Regimento, quanto na sala monitorial, é a ponteira ou vara, um instrumento utilizado pelos monitores e professores que servia para demonstração de lições, para apontar espaços e, sobretudo, para auxiliar na exposição dos comandos. Lancaster (1812) aponta que

é indispensável o uso de ponteiras ou varas [que consistem em] um pedaço de madeira [longo], com haste arredondada e que vai se adelgando até a ponta [formando uma espécie de batuta de maestro] suficientemente adequada para demonstrar as letras. A vara ou ponteira deveria ter uma dimensão física adequada: ser suficientemente fina e arredondada [para não machucar as mãos dos monitores], mas não tão afiada para não perfurar os materiais pedagógicos ou quebrar facilmente. (p. 3)

No The British Museum as ponteiras eram simbolizadas por uma bengala ou cane, um instrumento de cabo longo manuseado pelos monitores e professor, como forma intimidativa de exigir disciplina em sala de aula. Também no Regimento de 1871 a figura do cane é a metáfora da vara de sucupira, utilizada para imposição de ordem na sala de aula, mas algumas vezes adotada para castigar os alunos, embora no Regimento se destaque que os castigos utilizados em sala de aula deveriam ser de cunho moral ou psicológico.

Quanto aos castigos é interessante ressaltar que na obra The british system of education, Lancaster determina que na escola sejam usados castigos morais, abolindo-se a punição física, tão comumente utilizada no século 19. Assim, no Museu visitado há muitos exemplos de punição psicológica e um deles são as placas disciplinares ou tabuletas: instrumentos de coerção moral, empregados diante de situações consideradas condutas discentes inadequadas. As placas, com frases depreciativas, eram penduradas nos pescoço dos alunos como forma de constrangimento para que a má conduta não se repetisse.

Outro instrumento coativo era o chapéu em forma de cone, que deveria ser posto sobre a cabeça dos alunos, como forma de evitar erros e deslizes de comportamento. $O$ chapéu em forma de cone é descrito nos livros de Joseph Lancaster, mas ele foi alocado na sala Gallery.

Lancaster cita, ainda, o card, também presente na sala Gallery, que se constituía num artefato de madeira ou placa assemelhado a um colar cervical que se afixava no pescoço do ofensor:

Esta madeira poderia pesar de quatro a seis libras [unidade de peso equivalente a 453,59 g] o pescoço não é apertado ou confinado, mas é principalmente submetido à dor [...] quando o ofensor se move para direita ou para esquerda. Enquanto ele fica reto o equilíbrio é preservado, mas ao menor movimento [...] a placa funciona como um peso. (Lancaster, 1812, p. 68) 
No Regimento de 1871 os castigos narrados são mais brandos, embora não se tenha informação de que se eles eram efetivamente cumpridos. Descritos no artigo 73 em uma gradação que aborda desde a "reprehensão particular, reprehensão publica, de pé em cima do banco, ajoelhado no banco, [...] expulsão", os castigos físicos na escola brasileira sobreviveram quase até o século passado, embora com farta legislação proibindo-os.

Ainda sobre os castigos morais o Regimento de 1871 apresenta os chamados quadros de honra e desonra, uma publicização dos comportamentos dos alunos que poderiam ter seus nomes lançados nos quadros à medida que sua conduta oscilasse da forma positiva à negativa ou vice-versa. Os quadros eram instrumentos obrigatórios e representavam elementos simbólicos demarcados por cor, posição de lateralidade em relação ao professor e categorização de negativo ou positivo. O Regimento descreve os instrumentos, ressaltando que em toda sala deveria ter

dous quadro (sic) em branco, [um] com moldura dourada, chamados de honra, collocados ao lado direito do professor para lançar o nome dos meninos optimos, e outro negro de moldura preta, ao lado esquerdo, para lançar o nome dos meninos mãos (Regimento, 1871, art. 90, § 14).

Quanto à técnica da escrita há, na sala monitoral, um instrumento pedagógico inovador para época, denominado por Lancaster como printing in sand, traduzido como caixa de areia. Trata-se de um móvel retangular de madeira, escavado na parte frontal e preenchido com areia fina e branca para os alunos treinarem a escrita das primeiras letras na areia com os dedos, uma forma de exercitar a coordenação motora no período preparatório à alfabetização. No Museu há uma caixa de areia, da mesma forma como descrita no Regimento de 1871, denominado de areeiro.

$\mathrm{Na}$ mesa do professor deveria haver "uma campainha, um tinteiro, areeiro, lápis, canivete e ardósia" (Regimento de 1871, artigo 90, $\S 5^{\circ}$ ). As ardósias exigidas no Regimento de 1871 estão presentes no British Museum, sendo descritas por Lancaster como quadros individuais para os alunos escreverem. Quanto à função as ardósias eram similares aos atuais cadernos, só que confeccionadas em pedra, chamadas tábuas de ardósia, lousas de ardósia ou simplesmente ardósias. Foram descritas nos livros de Joseph Lancaster como o material de custo mais elevado e que, portanto, estava cercado de maior zelo na escola tendo-se, inclusive, o cuidado, de quando possível, mandar confeccionar nos bancos de madeiras alguns sulcos na parte frontal para acoplagem das ardósias, evitando-se assim que caíssem ao chão e se quebrassem.

No museu visitado as ardósias estão preservadas como pequenos quadros, dispostos em cima dos bancos escolares, tendo ao lado um pequeno bastão para riscar a pedra e um pedaço de pano para apagar os riscos. Destaque-se que as ardósias eram usadas em um momento intermediário da escrita, quando o aluno já havia passado pelas caixas de areia, mas ainda não estava pronto para treinar a escrita com a caneta de bico de pena. A escrita era treinada pelos monitores e conferida pelo professor.

A presença dos monitores é outro traço comum entre os dois elementos analisados, pois desde a formação da primeira escola de Hitchin, já encontramos indícios do uso de 30 monitores na sala de aula lancasteriana. Aliás, quando Lancaster descreveu o ensino monitorial, demonstrava, em diversas gravuras desenhadas à mão, como deveria ser a 
sala monitorial, indicando inclusive a posição dos auxiliares do professor na sala de aula. Eram os monitores alunos mais adiantados que deveriam coadjuvar o professor no ensino dos demais colegas, daí a denominação "ensino mútuo ou recursivo, significando dizer aquele que aprende, aprende e ensina os demais" (Bastos, 1999, p. 34).

Da mesma forma que o British School Museum demonstrou a adoção de monitores na sala lancasteriana, também no Regimento de 1871, o artigo 2, ressalta que

o aluno que mais se distinguir em intelligencia, merito e conducta, será o monitor e suas obrigações são coadjuvar o professor inspeccionando toda as classes, executando suas ordens, advertir seus condiscípulos quando se desviarem do cumprimento de seus deveres, concernentes Ao exercício d'aula, dando parte, no caso de transgressão de todas as coesacções.

A sala monitorial revela uma série de informações com riqueza de detalhes que gera o interesse em pesquisar mais e tentar se aprofundar no ambiente, pois ele representa uma parte da história educacional brasileira, na Inglaterra. Isto por que no século 19 o Estado via na escolarização uma perspectiva de intervenção social e, para tanto, a hierarquia deveria ser a tônica de uma sociedade ordeira que conhecesse os espaços públicos e nele interagisse reconhecendo as autoridades e seus escalões. Carvalho (2007) propõe que essa perspectiva de construção da sociedade civilizada era um dos desideratos da monarquia. Assim, a escolarização vem reforçar as capilaridades do poder, demonstrando que, na escola, tal qual nas sociabilidades, há espaços e escalões que deveriam ser observados. Estas configurações de poder, disciplina, ordem, formalização e hierarquia, dentre outros aspectos, estão presentes, tanto no Regimento de 1871, quanto nos instrumentos pedagógicos da sala monitorial londrina.

\section{Considerações finais}

Entendendo a História como um discurso cambiante e problemático que tem a capacidade de desvelar o passado, pois este chega até nossos dias por meio de fragmentos, com este trabalho não tivemos a pretensão de abarcar a totalidade nem exaurir o tema tão complexo que é a obra pedagógica de Joseph Lancaster.

A estratégia da monarquia brasileira, ao instaurar o método lancastriano no ensino, firma o modelo pedagógico europeu e intensifica o projeto intelectual do Brasil, formalizando nova roupagem de educação para atender as camadas mais populares.

As representações contidas na sala monitorial são equivalentes àquelas descritas no Regimento de 1871, como se no âmago do entendimento entre os dois objetos analisados houvesse um diálogo referencial que os liga de forma incontestável. Assim, se no Brasil lidamos com uma ausência de imagens sobre o método lancasteriano, os instrumentos abrigados no British School Museum são a complementação lúdica desse vazio transformando os ferramentais da sala monitorial numa presença objetal na lacuna brasileira. Ou seja, na ausência de fontes e memórias pictóricas nos anais do Espírito Santo, na exigüidade de figuras do Regimento Interno de 1871 - que apenas descreve o abstrato - a sala monitorial conseguiu demonstrar um conjunto de símbolos concretos, uma estrutura culturalmente fornecida que compartilha aspectos entre os dois lugares: Brasil e Inglaterra do século 19 em comunhão.

Logo, os dois elementos analisados se complementam como se um descrevesse o outro, ou seja, a representação lúdica do Museu torna presente o ausente, exibe sua 
concretude pelos objetos que se mostram como imagem descrita no Regimento de 1871, guardando relações de pertinência e semelhança com o documento. As estruturas pedagógicas são análogas e têm o mesmo propósito: gerar escolarização, organização, moralidade, religiosidade e civilidade. Assim, o tinteiro, o areeiro, o púlpito docente, as tábuas de ardósia, as caixas de areia, as recompensas e punições analisadas, tanto no The British Museum, quanto no Regimento de 1871 parecem pares de instrumentais que dançam uma afinada melodia.

Isto por que se tomarmos o Regimento de 1871 como uma representação ou esquema intelectual que cria figuras mentais no leitor, foi o British School Museum o espaço a tornar inteligível a decifragem desses símbolos imaginários dando-lhes significado e, com isso, gerando, na história educacional lancasteriana entre Brasil e Inglaterra, uma identidade compartilhada, representativa entre os dois países.

Foi possível observar que a partir da introdução do método lancasteriano no ensino as estratégias descritas no Regimento Interno de 1871 se coadunaram com os símbolos encontrados no Museu. Assim, é salutar estabelecer que entre os dois objetos analisados ficam claras a percepção da disciplina e poder advindos do método lancasteriano na escola. Isto por que havia perspectiva de educar as classes populares produzindo, tanto a inserção delas na sociedade letrada, quanto a civilidade da boa sociedade ordeira, educada e pacífica. Esses elementos estão contidos na disposição ordenada das mesas, bancos, cadeiras, na configuração da sala, e, principalmente na organização curricular, tanto no Regimento Interno de 1871, quanto nos materiais arquivados no The British School Museum.

A formalização foi outro elemento presente nos dois campos, pois à medida que a sociedade desejou mesclar a leitura e escrita com os elementos orais, o ensino de Joseph Lancaster casou muito bem com essa perspectiva, no afã de alfabetizar o maior número possível de cidadãos, esse projeto político na Inglaterra atendia à sociedade protoindustrial e no Brasil atendia aos anseios do Estado neocolonial, recém independente que precisava se afirmar. Desta forma é possível verificar que entre os dois objetos de pesquisa analisados há uma sintonia demonstrada pela síntese dos materiais pedagógicos na sala monitorial.

Desta forma a influência, o prestígio, a idoneidade do professor são aspectos demonstrativos da moralidade do ensino lancasteriano, combinada com a religiosidade, elemento presente nos duas fontes analisadas com a demonstração da bíblia na sala lancasteriana, e a formação dos professores brasileiros - quase todos religiosos - ou ainda, a formação curricular da escola brasileira, quase toda ela repleta de autores religiosos com seus livros temáticos católicos, a exemplo do cônego Pinheiro, do cônego Schmidt, do frei Francisco Luis e tantos outros autores que constam no rol de livros do Regimento Interno de 1871. Logo, foi possível perceber que as estratégias entre os dois elementos analisados - museu inglês e regimento brasileiro - são similares, guardam um grau de equivalência muito próximo.

Todavia, essa partilha identitária se expressa no discurso assumindo múltiplas leituras lá e aqui, já que as representações não são neutras e produzem estratégias e 
práticas que denotam muitas vezes relações de poder diferenciadas nos dois espaços analisados.

É possível destacar que a forma de apropriação brasileira do modelo foi diferenciada em alguns elementos. Não resta dúvida da intenção do Estado em preconizar disciplina e poder na escola demonstrando, pelas relações de hierarquia, linhas de separação entre as camadas da população, entre o professor e seus alunos, entre os alunos e os monitores. Não resta dúvida também a inserção dos alunos pobres na escola na perspectiva de prover um futuro melhor para as crianças e sua família.

Mas se essa perspectiva se inscreveu em Londres do século 19, no Brasil a cultura produzida se diferenciou, tanto que o método lancasteriano escrito no Regimento de 1871 pouco traz sobre as emulações e prêmios concorrenciais demonstrados nas obras lancasteriana. Daí que a sociedade industrial londrina, mais competitiva, em muito divergia da sociedade agrária brasileira, treinada para, no máximo, ter letramento para ocupar cargos públicos, já que no Brasil não havia indústrias.

Outro aspecto diferenciado entre os dois momentos é que gestado em pleno regime político monárquico, o método lancasteriano londrino floresceu e se nutriu dos princípios conservadores e ali permaneceu mais tempo. Já no Brasil, embora a monarquia apresentasse o Método Monitorial como sustentáculo político ele não foi eficaz no sentido de fortalecer igreja católica e Estado, tanto assim que em 1888 na mudança da monarquia para a República o sistema lancasteriano se esgotou, e o Estado se tornou laico.

Finalmente é possível destacar que o método padronizou alguns elementos importantes para a educação nos dois países e, neste aspecto, foi bastante eficaz em treinar a escolarização e debelar iliteralidade, reconhecendo-se nele a racionalidade de seu projeto educacional. Todavia, essa mesma racionalidade que o impeliu foi o elemento contingencial que o tornou fora do novo modelo político, pois quando no Brasil o regime monárquico foi encerrado, um novo momento educacional se inseriu na História. Já na Inglaterra, embora o regime monárquico tenha permanecido e se remodelado, o método lancasteriano também se exauriu, o que atesta sua pouca capacidade de adaptação à mudança sócio-política. Conservador que foi, se adequou muito bem ao século 19, e lá permanece como uma lembrança nostálgica.

\section{Referências}

ARANHA, Maria Lúcia de Arruda. História da educação. São Paulo: Moderna, 1996.

BASTOS, Maria Helena Camara. A escola elementar do século 19: o método monitorial/mútuo. Passo Fundo: Ediupf, 1999.

BASTOS, Maria Helena Camara. A instrução pública e o ensino mútuo no Brasil: uma história pouco conhecida (1808-1827). Hist. Educ. (Online), v.1, n. 1. 1997. Disponível em <http://seer.ufrgs.br/asphe/article/view/30631>. Acesso em 16 set., 2012.

BASTOS, Maria Helena Camara. A educação elementar e o método lancaster no correio brasiliense (1816). Hist. Educ. (Online), v. 9, n. 17. 2005. Disponível em <http://seer.ufrgs.br/asphe/article/view/29207>. Acesso em 16 set., 2012.

BICHARA, Terezinha Tristão. História do poder legislativo do Espírito Santo. Vitória: Leoprint, 1984.

BITTENCOURT, Gabriel. História geral e econômica do Espírito Santo: do engenho colonial ao complexo fabril portuário. Vitória: Multiplicidade, 2006. 
BRITISH SCHOOLS MUSEUM. Hitchin british schools: a history of the Buildings. Hitchin, United Kingdom: Hitchin British Schools Trust, 1999.

CENTRO PEDAGÓGICO. Pequena história do Espírito Santo. Vitória: Ufes, [s.I: s.n. 19-?].

CERTEAU, Michel de. A escrita da história. Rio de Janeiro: Forense Universitária, 2007.

CHARTIER, Roger. História cultural: entre práticas e representações. Lisboa: Difel; Rio de Janeiro: Bertrand Brasil, 1990.

CARVALHO, José Murilo de. Nação e cidadania no império: novos horizontes. Rio de Janeiro: Civilização Brasileira, 2007.

FARIA FILHO, Luciano. Escola, política e cultura: a instrução elementar nos anos iniciais do império brasileiro. Belo Horizonte: Argvmentvm, 2006.

FOUCAULT, Michel. Vigiar e punir. Petrópolis: Vozes, 2004.

FOUCAULT, Michel. Microfísica do poder. Petrópolis: Vozes, 1998.

FOUCAULT, Michel. Arqueologia do saber. Rio de Janeiro: Forense Universitária, 2008.

GINZBURG, Carlos. O fio e os rastros: verdadeiro, falso, fictício. São Paulo: Companhia das Letras, 2002.

GINZBURG, Carlos. Mitos, emblemas, sinais: morfologia e história. São Paulo: Companhia das Letras, 1989.

LANCASTER, Joseph. The british system of education: Being a complete epitome of the improvements and inventions practiced by Joseph Lancaster: to which is added, a report of the trustees of the Lancaster School at Georgetown. Published by: Joseph Milligan and by William Cooper. Washington, 1812.

LANCASTER, Joseph. The lancasterian system of education: with improvements. Baltimore: WN Ogden Nilles, 1821.

LANCASTER, Joseph. Improvements in education, as it respect the industrious classes of community. Piccadilly, London: Darnton \& Harvey, 1803.

LANCASTER, Joseph. Epitome of some of the chief events and transactions in the life of Joseph Lancaster: containing an account of the rise and progress of the Lancasterian system of education and the author's future prospects of usefulness to mankind. New York: Baldwin \& Peck. 1833.

TAYLOR, Joyce. Joseph Lancaster: the poor child's friend. Hitchin, United Kingdom: The Hitchin British Schools Trust, 2012.

VERGARA, Sylvia Constant. Projetos e relatórios de pesquisa em administração. São Paulo: Atlas, 2009.

DIRCE NAZARÉ DE ANDRADE FERREIRA é professora na Universidade Federal do Espírito Santo, doutora em Direito pela Faculdade de Direito de Vitória e doutora em História Política pela Universidade Federal do Espírito Santo.

Endereço: Av. Fernando Ferrari, 514 - 29075-910 - Vitória - ES - Brasil.

E-mail: dircenazare@hotmail.com. 
CLEONARA MARIA SCHWARTZ é professora na Universidade Federal do Espírito Santo e coordenadora do curso de Pós-Graduação em Educação da mesma universidade. Tem estágio pós-doutoral em educação pela Universidade de São Paulo.

Endereço: Av. Fernando Ferrari, 514 - 29075-910 - Vitória - ES - Brasil.

E-mail: cleonara@terra.com.br.

ALOISIO KROHLING é professor da Faculdade de Direito de Vitória. Tem estágio pós-doutoral em Filosofia pela Faculdade de Santo Anselmo, em Roma.

Endereço: Rua Juiz Alexandre Martins de Castro Filho, 215 - Vitória - ES - Brasil.

E-mail: krohling@gmail.com.

Recebido em 13 de agosto de 2013.

Aceito em 20 de julho de 2015. 